Article

\title{
Quantification of Energy Loss in Two Grated Inlets under Pressure
}

\author{
Jackson Tellez-Alvarez ${ }^{1,2, * \mathbb{D}}$, Manuel Gómez ${ }^{1}(\mathbb{D})$ and Beniamino Russo ${ }^{1,3}$ (D) \\ 1 FLUMEN Research Institute, Department of Civil and Environmental Engineering (DECA), \\ Technical University of Catalonia (UPC)—BarcelonaTECH, 08034 Barcelona, Spain; \\ manuel.gomez@upc.edu (M.G.); beniamino.russo@upc.edu (B.R.) \\ 2 Consorci Besòs Tordera/CCB Serveis Mediambientals, SAU, 08403 Granollers, Spain \\ 3 Group of Hydraulics and Environmental Engineering (GIHA), Technical College of La Almunia (EUPLA), \\ University of Zaragoza, La Almunia de Doña Godina, 050100 Zaragoza, Spain \\ * Correspondence: jackson.david.tellez@upc.edu or jdtellez@besos-tordera.cat
}

Received: 13 March 2020; Accepted: 1 June 2020; Published: 4 June 2020

\begin{abstract}
Grated inlets have the normal function of collecting the surface runoff into sewer networks, but when the flow exceeds the capacity of the sewer pipes and conduits get pressurized, an outflow from the sewer manholes and grates can occur. In this case, the grate produces an energy loss in the outflow from sewer to street that could be hydraulically quantified characterizing this kind of flow. Energy loss analysis in trash racks can be found in technical literature, but no specific studies on sewer grate inlets have been found. For this reason, some experiments in full scale were developed in the hydraulic laboratory of the Technical University of Catalonia (UPC) in order to quantify hydraulic energy losses associated with flow through grated inlets during surcharging conditions. The main goal of this research work was to experimentally quantify the values of the local loss coefficient $k$ for two different surcharged real scale grated inlets existing in Barcelona. For the tested overflows between 20 and $50 \mathrm{~L} / \mathrm{s}$, a range from 0.25 to 3.41 was observed for $k$ coefficients under different average velocities of reference and different flow conditions.
\end{abstract}

Keywords: sewers; drainage; hydraulics; grate inlet

\section{Introduction}

In the last years, several studies in the field of urban flood risk management have focused on urban pluvial floods produced by a poor surface drainage capacity [1-6]. When a dual drainage approach is used to study the interactions between surface flow (street level) and underground flows (sewer level), the inlets are the key elements linking both systems. Entrance from the street to sewer has been studied by many authors and several procedures are established in the technical literature. In most cases, the purpose is to quantify how much water is intercepted by a specific design of grated inlet [7-12]. Some methods like the Hydraulic Engineering Circular No. 22 (HEC-22) procedure [13] or Technical University of Catalonia (UPC) methodology [14] were published and incorporated in commercial software like InfoWorks.

On the other hand, the flow transfer between the sewer network and surface level produced when the sewer is pressurized has not deeply examined or, at least, has not received the same level of attention. Some procedures have assumed that flow behavior through the inlet is similar to the hydraulics of an orifice or a weir, proposing a specific limited set of experimental data [15]. Another possible approach is to consider the local hydraulic effect of the grated inlet with its holes and bars over the flow. In this case, we can assume that the presence of the grate can produce a local energy loss that could be quantified to determine how much water is leaving the sewer to the streets. If we can express the 
local energy loss in a traditional way, an energy loss coefficient operated by the square of velocity and divided by two times the gravity, this could be used to characterize the hydraulics of this process and the assessment of the outflow from the sewer system. Highlighting that urban drainage networks should be designed and managed to avoid overflows and urban floods [16], and the old combined systems should be rationally rehabilitated [17], a correct estimation of sewer overflows produced by surcharged pipe conditions is essential for the correct flood assessment of urban areas in the case of pluvial floods $[18,19]$.

In 1990, Bo Pedersen and Mark [20] stated that the design of storm sewer systems especially suffered from a lack of knowledge of the head losses in manholes.

During the past years, some researchers have started to study the energy loss for different manholes such as Marsalek [21], who described that the energy loss of manholes is proportional to the velocity and inlet flow in the manholes. Moreover, other studies have focused on the behavior of manholes through a numerical simulation, in order to represent the local loss at junctions and manholes like those in [20,22-24]. In addition, Djordjevic et al. [25] and Rossman [26] developed the Simulation of Interaction between Pipe flow and Surface Overland flow in Networks (SIPON) or Storm Water Management Model (SWMM 5) models that considered the interaction between sewer pipes and surface flow, focusing on the behavior of the surcharged manholes $[25,26]$.

Furthermore, O'Loughlin and Stack [27] demonstrated that the values of energy loss could have infinity solutions because it is proportional to the geometry and hydraulic condition established. According to this work, local energy loss related to sewer manholes are the water depth, boundary conditions upstream and downstream, bed discordance over the manhole junction, magnitude of the flowrate (main and lateral), and angle between the pipes (main and lateral), among others. The oscillation of water depth in supercritical flow in a $45^{\circ}$ junction manhole was studied more deeply by [28,29] through experiments and developed some empirical approaches. Therefore, these studies were oriented to study the flow inside the sewer network and the particularities associated with the manhole structures, but nothing was related to grate inlet performance.

In addition, another experimental study to characterize the behavior and estimate the values of energy loss in manholes with three different combination of pipes was developed by Arao et al. [30], where they concluded that the result of energy loss for the three combinations changed considerably.

More recently, the interaction between surface flows versus sewer flows in the manhole structures considering the outflow from the sewer network was studied [31-33]. This is the closest reference to the energy loss associated with the outflow from the sewer system, but it investigated the case of sewer overflow when the manhole lid had been removed due to the pressure of the flow, which is associated with specific flooding conditions. In the literature, it was possible to find information about the energy losses in manholes [32], but energy losses associated with grated inlets were not investigated. Moreover, another work developed some 2D numerical simulations of the exchange between a flooded street and its surcharged surface drainage system grates and manholes. The results provided values of the discharge coefficient of manholes of 0.39 to 0.46 for all the considered overflow conditions [34].

In this context, a new experimental campaign to study the behavior of two grated inlets under surcharged flow conditions was carried out with the aim to achieve the estimation of energy loss [34].

\section{Overview}

Energy losses in pipes and channels used for fluid transportation are essentially due to friction as well as to the diverse singularities encountered.

The energy loss occurs when the fluid motion is crossing a section and the energy of the fluid changes. The energy loss depends on some conditions as the type of fluid, geometry of the conduit or special elements like valves, etc. and the characteristics of the fluid motion. Two different types of energy loss exist:

- $\quad$ The friction losses; and 
- $\quad$ The local losses.

where the friction losses depend on the viscosity of the fluid, roughness of the conduit walls, and if it is laminar or turbulent. Normally, this loss occurs along the conduits and it is relevant with the distance. The local losses are also known as minor head losses due to the fact that for pipes of important length, their value can be neglected comparatively to that due to friction. However, their effect can be significant for short pipes [35]. Local losses occur with a disturbance of flow due to a local change of geometry in the conduit with a formation of eddies by an obstacle or structure (for instance, a sewer grate can be considered as an element producing a local loss). Local loss is described usually as:

$$
\Delta h_{k}=k \frac{v^{2}}{2 g}
$$

where $\Delta h_{k}$ is the local loss in $\mathrm{m} ; v$ is the average velocity in $\mathrm{m} / \mathrm{s} ; g$ is the gravity acceleration; and $k$ is the local loss coefficient characteristic of the type of the singularity and its value varies consequently.

In Table 1 , it is possible to see the typical values of energy loss coefficient $k$ used in a pressure-flow condition in water distribution networks, for different usual elements like elbows, etc. In principle, this is not the flow we have in the sewer, but is just to have an idea of the order of magnitude of local loss coefficients [36].

Table 1. Typical local loss coefficient $k$.

\begin{tabular}{|c|c|c|}
\hline Type & Classification & Values $k$ \\
\hline \multirow{6}{*}{ Elbow } & Regular $90^{\circ}$, flanged & 0.3 \\
\hline & Regular $90^{\circ}$, threaded & 1.5 \\
\hline & Long radius $90^{\circ}$, flanged & 0.2 \\
\hline & Long radius $90^{\circ}$, threaded & 0.7 \\
\hline & Long radius $45^{\circ}$, flanged & 0.2 \\
\hline & Regular $45^{\circ}$, threaded & 0.4 \\
\hline \multirow{2}{*}{$180^{\circ}$ return bend } & $180^{\circ}$ return bend, flanged & 0.2 \\
\hline & $180^{\circ}$ return bend, threaded & 1.5 \\
\hline \multirow{4}{*}{ Tees } & Line flow, flanged & 0.2 \\
\hline & Line flow, threaded & 0.9 \\
\hline & Branch flow, flanged & 1.0 \\
\hline & Branch flow, threaded & 2.0 \\
\hline Union, Threaded & & 0.08 \\
\hline \multirow{11}{*}{ Valves } & Glove, fully open & 10 \\
\hline & Angle, fully open & 2.0 \\
\hline & Gate, fully open & 0.15 \\
\hline & Gate, $\frac{1}{4}$ closed & 0.26 \\
\hline & Gate, $\frac{1}{2}$ closed & 2.1 \\
\hline & Gate, $\frac{3}{4}$ closed & 17 \\
\hline & Swing check, forward flow & 2 \\
\hline & Swing check, backward flow & $\infty$ \\
\hline & Ball valve, fully open & 0.05 \\
\hline & Ball valve, $1 / 3$ closed & 5.5 \\
\hline & Ball valve, $2 / 3$ closed & 210 \\
\hline
\end{tabular}

Normally, in the sewer network, the surcharge condition occurs during extreme rainfall events that exceed the sewer system capacity generally designed using synthetic project storms with return periods up to 10-20 years. In Spain, maximum rainfall intensities for a duration of 5 min and a return period of 10 years can reach values of approximately $200 \mathrm{~mm} / \mathrm{h}$, like in the case of Barcelona [37,38]. In these cases, some conduits begin to be pressurized, the pressure level rises until the level of the street, 
and elements such as grated inlets and manholes start to work under pressure, producing flooding on the surface.

The surcharge condition in a sewer network was studied more in the manholes, but associated with the flow along the sewer, not to the outflow to the streets. Pfister and Gisonni [39] and Zhao et al. [40] studied the condition of surcharged flow through manholes (focusing on head loss) in a bifurcation case and for junction manholes for free surface flows in circular conduits [39,40]. Furthermore, Ramamurthy et al. [41], Pfister and Gisonni [39], and Zhao et al. [38] calculated the loss coefficient considering the total energy loss as defined in Equation (2). All of these references demonstrate that the main interest of previous studies was oriented to the loss coefficients associated with the flow in the sewer networks, but not to the outflow through the grate inlets. This context justified the development of a specific experimental campaign focused on the estimation of local head loss and discharge coefficients for two surcharged grated inlets at the hydraulic laboratory of the Technical University of Catalonia [34,42].

\section{Methodology}

\subsection{Experimental Setup}

This section presents the experimental facility that was used for the laboratory campaign and test protocol. The experiment campaign was carried out in the hydraulic laboratory of the Technical University of Catalonia (Barcelona) through a platform already used in previous studies $[9,10,42,43]$ (Figure 1). The platform was 5.5 long and $3 \mathrm{~m}$ wide and allowed us to change the longitudinal slope from 0 to $10 \%$ and the transversal slope from 0 to $4 \%$. It is possible to test grated inlets in real scale, so no scale effects were expected in the study. The platform with a grated inlet is shown in Figure 1.

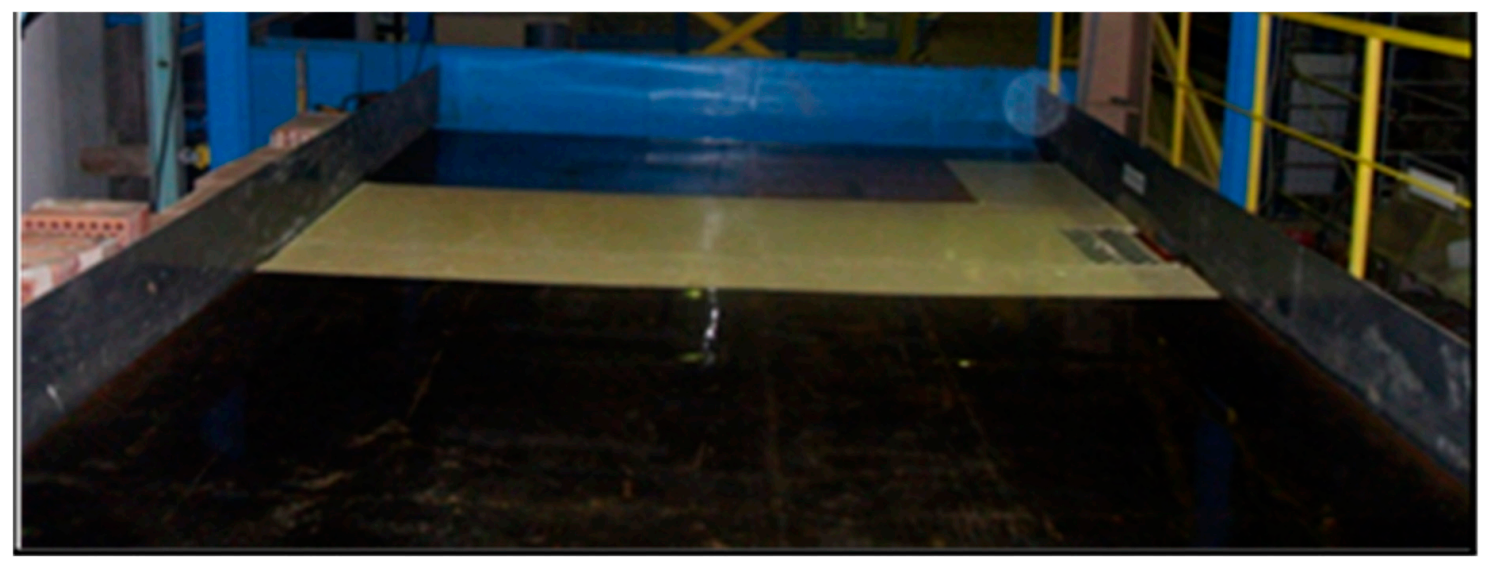

Figure 1. The platform used for the tests of grated inlets.

With respect to previous experimental campaigns $[9,10,43]$, the physical model was modified to analyze the outflow through the grated inlet and to reproduce the effect of a pressure-flow condition in the sewer, generating an outflow to the street. The inlets used in the tests were the so-called Barcelona1 and Barcelona2, two of the most common grate inlets in Barcelona.

In Figure 2a, representation of the surcharged outflow and a scheme of the laboratory facility is shown. In all the tests, no flow on the surface layer was assumed, so the only exchange was from the pressurized pipe (representing the sewer pipe) to the platform (representing the surface street). Tests were carried out in steady flow conditions in all cases. The transverse slope was constant and equal to $2 \%$ for the different tests (this value is the most common one for pavement design used in Barcelona [42]. 
Furthermore, the boundary condition (BC) of the model was essentially one: a constant surcharged overflow through the grate. At the end of the platform, an open channel collected the flow, directing it into a closed circuit feeding the physical model.

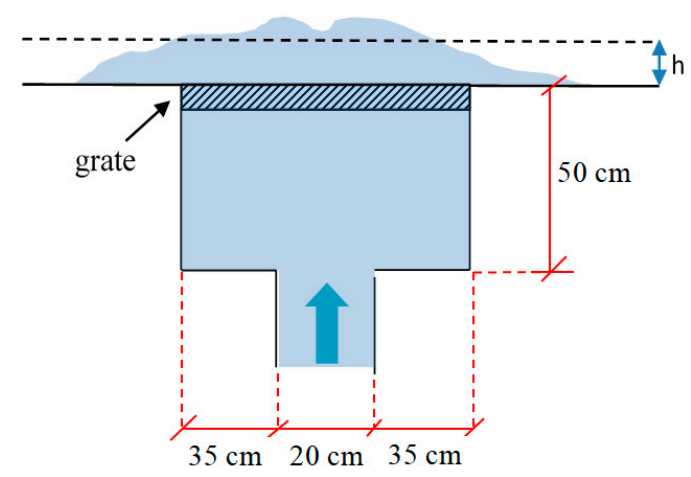

(a)

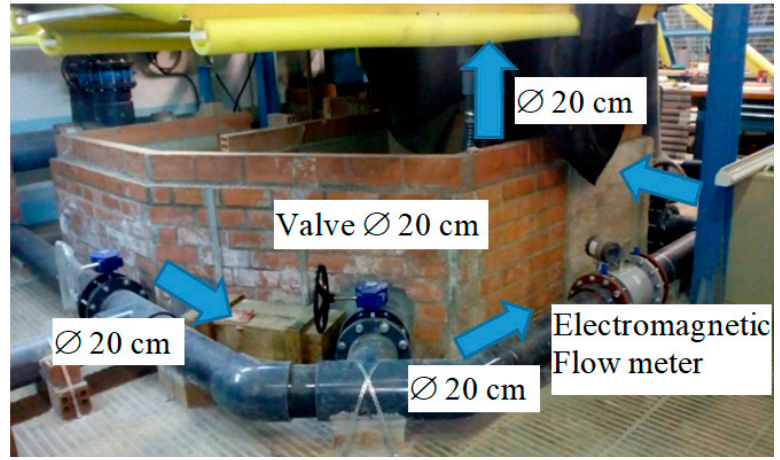

Arrows indicate the flow direction.

(b)

Figure 2. (a) Box below the grate inlet and hydraulic pipes system; (b) hydraulic pipe system.

Surcharged overflow reached the inlet through a $200 \mathrm{~mm}$ circular pipe. An inlet box of $90 \times 30 \mathrm{~cm}$ and $50 \mathrm{~cm}$ height was located below the grate inlet (Figure 2). Additionally, the box held the grate and had the inflow in the center of the lower part.

The platform was modified in such a way that flow through the inlet could be reproduced with the aim of representing the pressurized flow in the sewer and an outflow leaving the conduit. Flows considered through the grate were from 20 to $50 \mathrm{~L} / \mathrm{s}$. Twenty points over the grate were taken into account (Figure 3) and an average value of the 20 measures was considered as representative of the water level over the grate (Figures $2 a$ and $4 b$ ). The water level over the grate inlet was measured manually, with a limnimeter with a $1 \mathrm{~mm}$ accuracy, as shown in Figure 4a. In order to simulate the surcharged overflow by the grate, the experimental facilities presented some modifications with respect to the previous campaign $[9,10,43]$ with additional pipes and valves installed, as shown in Figure $2 \mathrm{~b}$. 


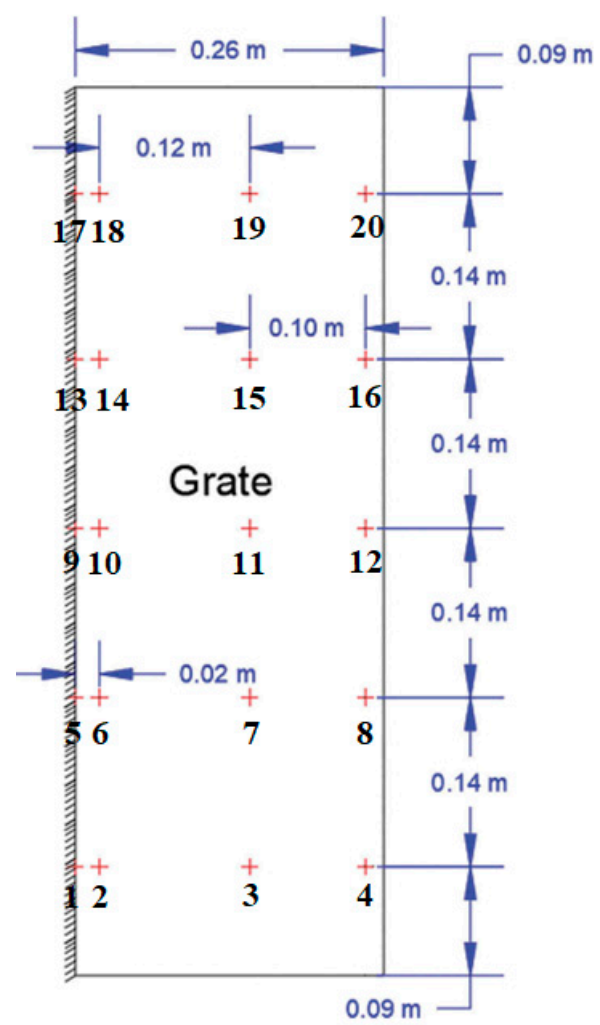

Figure 3. Location of 20 points over the grate [42].

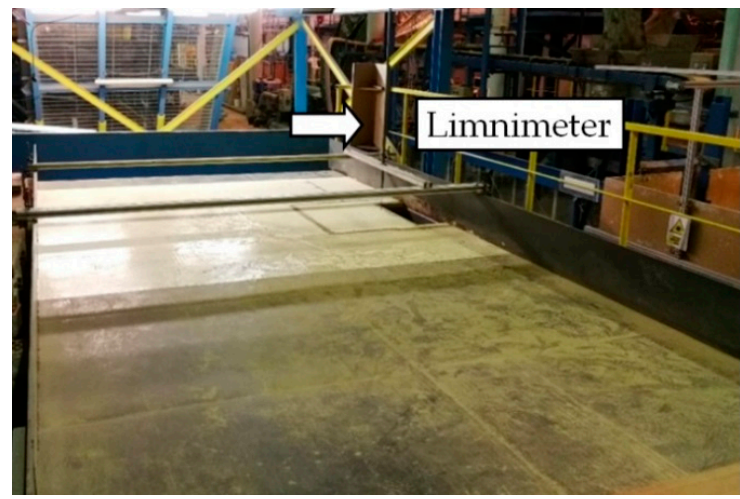

(a)

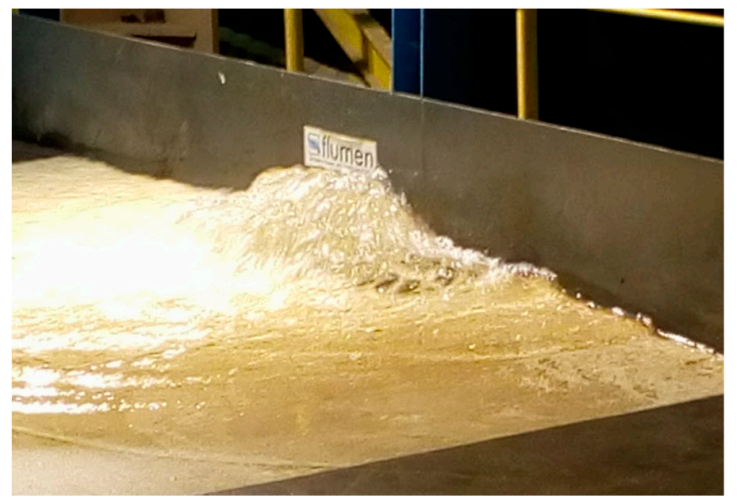

(b)

Figure 4. (a) Structure to support the limnimeter to read water levels over the grate; (b) Test of $40 \mathrm{~L} / \mathrm{s}$, $0 \%$ longitudinal slope for the Barcelona1 grate.

The laboratory pumping station is able to discharge up to $200 \mathrm{~L} / \mathrm{s}$ from a storage tank located at the basement of the building to another tank on the rooftop, after the flow down by gravity to the physical model that was controlled by an automatic valve and flow meter installed in the circuit panel. The procedure of the calibration of the flow rate through the grate was made using the electromagnetic flow meter installed in the pipe circuits (Figure $2 b$ ), in order to guarantee a precision less than $0.5 \mathrm{~L} / \mathrm{s}$ and to avoid significant not estimated local head losses.

For all the tests, the pipes of the circuit were under pressure with turbulent flow. Specifically, the range of the Reynolds number for pipe flow was from 71,037 (for $20 \mathrm{~L} / \mathrm{s}$ ) to 177,593 (for $50 \mathrm{~L} / \mathrm{s}$ ).

In total, six combinations for each flow rate and 30 cases for each type of grate were considered. Grated inlets and their geometric parameters are shown in Figure 5 and Table 2. 


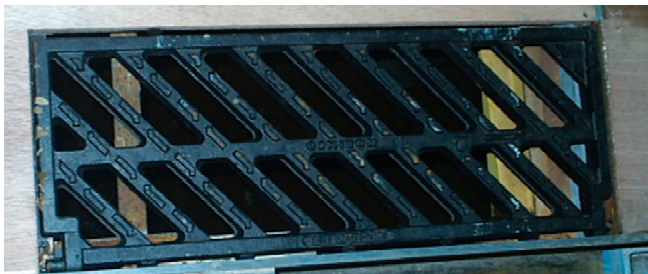

(a)

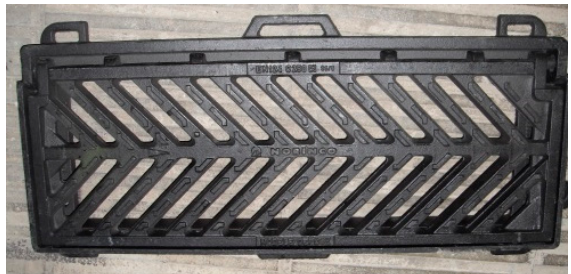

(b)

Figure 5. Grates tested in the experimental campaign; (a) Grate type "Barcelona1"; (b) Grate type "Barcelona2".

Table 2. Geometry of the grate inlets tested.

\begin{tabular}{cccc}
\hline $\begin{array}{c}\text { Grate } \\
\text { Type }\end{array}$ & $\begin{array}{c}\text { Length } \\
\mathbf{( c m )}\end{array}$ & $\begin{array}{c}\text { Width } \\
\mathbf{( \mathbf { c m } )}\end{array}$ & $\begin{array}{c}\text { Holes Area } \\
\mathbf{( m}^{\mathbf{2}} \mathbf{)}\end{array}$ \\
\hline Barcelona1 & 74.5 & 26 & 0.0852 \\
Barcelona2 & 74.5 & 26 & 0.0857 \\
\hline
\end{tabular}

A picture of the tests is presented in Figure $4 \mathrm{~b}$, where the differences between the water levels over the grate and over the platform during the tests can be observed. Moreover, oscillations of several millimeters were appreciated during the tests, so water level measure considered the average value with a time of the water depths.

\subsection{Test Protocol and Energy Loss Coefficients}

The estimation of the energy loss coefficient in surcharged sewer overflow by grates depends on the inlet geometry. On the other hand, it is important to know the local losses that the water shows in its circulation through the grate. For the case of any hydraulic section, the local loss can be described by Equation (1), and consequently, the energy loss coefficient $k$ can be obtained from the expression:

$$
k=\Delta h_{k} \frac{2 g}{v_{\text {outflow }}^{2}}
$$

where $\Delta h_{k}$ is the difference in $\mathrm{m}$ between the water levels above the box outlet where the grates are installed, without and with the grates, for the same inlet flow and same platform slopes; $v_{\text {out flow }}$ is the average velocity in $\mathrm{m} / \mathrm{s}$, defined as $v_{\text {outflow }}=\frac{Q_{\text {outflow }}}{A_{h}}$ where $A_{h}$ is the grate hole's area in $\mathrm{m}^{2}$; $Q_{\text {outflow }}$ is the flow passing through the grate; $g$ is the gravity acceleration $\left(9.81 \mathrm{~m} / \mathrm{s}^{2}\right)$; and $k$ is the local loss coefficient.

The experimental campaign was divided into two phases. The first was focused on outflows without grates, while the second one considered tests with grated inlet. The ranges of the test flows were 20,30, 40, and $50 \mathrm{~L} / \mathrm{s}$; the longitudinal slopes were $0,2,4,6,8$, and 10\%; and the transverse slope was fixed in $2 \%$. The water depth was measured in 20 points above-mentioned, so later considering an average value of the water level above the inlet. All the average water depths are available in Table A1 of the Appendix A. It was possible to observe that this average water level was smaller than the average value obtained in the test without the grate, so it is possible to conclude that the difference between these values is the local loss produced by the grate inlet.

\section{Results}

\section{1. $k$ Values of the Two Grates}

The test results are shown in Figures 6 and 7 and demonstrate that local loss is very sensitive in Equation (2), considering that the surface level is oscillating due to the effect of turbulence. For these 
reasons, the results (in terms of $k$ values) are presented, also providing error bars due to the flow depth oscillations.

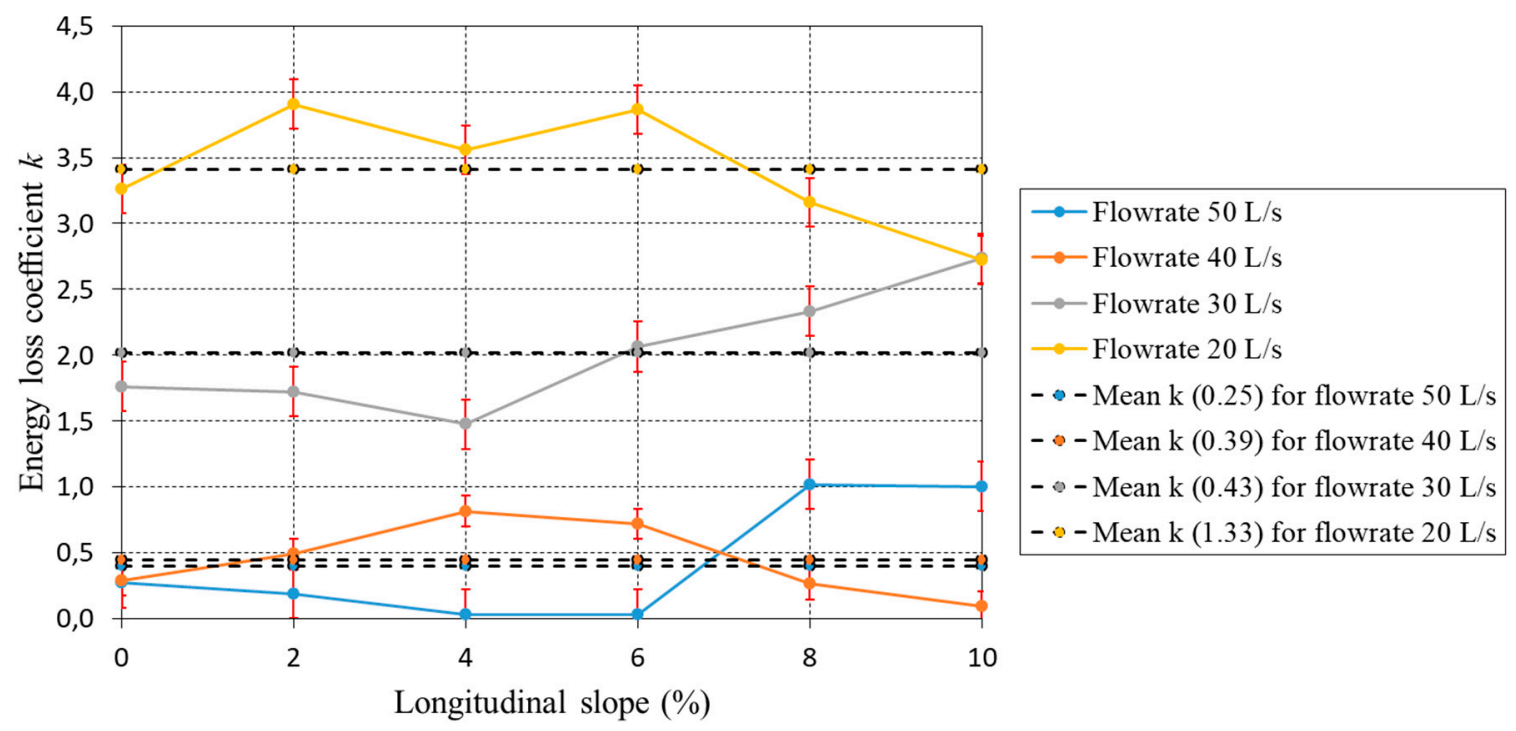

Figure 6. Graph of energy loss coefficient $k$ of grate Barcelona1.

Energy loss coefficients depend on the flow and the value decreases with the increase of flow through the inlet, as can be seen in Figure 8. Looking at the results, it is possible to observe some small variations $(0.19(50 \mathrm{~L} / \mathrm{s}), 0.73(40 \mathrm{~L} / \mathrm{s}), 1.01(30 \mathrm{~L} / \mathrm{s})$, and $1.19(20 \mathrm{~L} / \mathrm{s}))$ of the energy loss coefficient with the longitudinal slope, and according to this, a constant value was proposed for each outflow through the grate inlet that involves all the combinations of geometry (longitudinal and transversal slope) for each analyzed surcharged overflow, as shown in Table 3 and Figure 8. Regardless of the variations observed with the different longitudinal slopes, it is possible to conclude that the influence of the slope is limited. The two grates tested showed similar values for the $k$ in all cases. Both showed the same influence with the outflow, greater flow, and lower $k$ value, although the differences were quite small for the maximum tested outflows. Grate Barcelona2 showed smaller values of $k$ than grate Barcelona1, but both were quite similar ( $k$ from 3.41 to 0.22 for Barcelona1, and from 1.33 to 0.25 for Barcelona2). The geometry of both grates showed the same length and width, and small differences in the area of holes of only around $0.6 \%$. In particular, the obtained results showed that for the greater tested outflows (40 and $50 \mathrm{~L} / \mathrm{s}$ ), the $k$ coefficient was quite constant for both outflows and the two tested grates, so we could conclude that it depends only on the geometry of the grate. For smaller outflow rates $(20$ and $30 \mathrm{~L} / \mathrm{s})$, the values of $k$ seemed to decrease when the outflows increased, although their range was quite limited. A possible explanation of these different trends could be due to the different percentage of grates hole occupied by outflow during the tests. For greater outflows (40 and $50 \mathrm{~L} / \mathrm{s}$ ), practically the whole void area of the two grates was crossed by the flow, while for low outflows (20 and $30 \mathrm{~L} / \mathrm{s}$ ), this area was only partially crossed. For this reason, the results of the $k$ coefficients obtained for greater outflows can be considered as more reliable. 


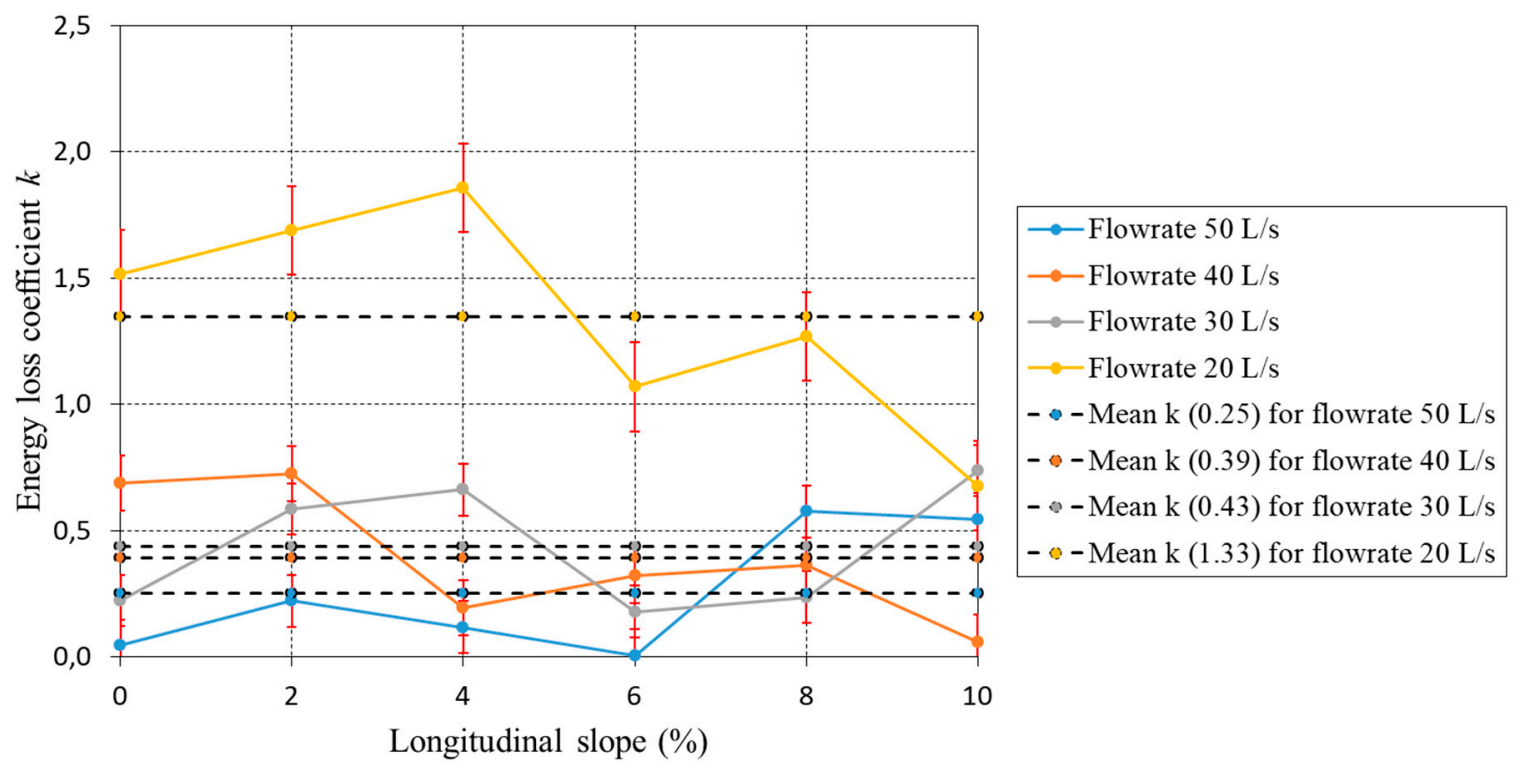

Figure 7. Graph of energy loss coefficient $k$ of grate Barcelona2.

Table 3. Energy loss coefficient $k$ for the tested grates.

\begin{tabular}{ccc}
\hline $\begin{array}{c}\text { Flowrate } \\
(\mathbf{L} / \mathbf{s})\end{array}$ & $\begin{array}{c}\text { Energy Loss Coefficient of Grate Barcelona1 } \\
(\boldsymbol{k})\end{array}$ & $\begin{array}{c}\text { Energy Loss Coefficient of Grate Barcelona2 } \\
(\boldsymbol{k})\end{array}$ \\
\hline 20 & 3.41 & 1.33 \\
30 & 2.02 & 0.43 \\
40 & 0.44 & 0.39 \\
50 & 0.42 & 0.25 \\
\hline
\end{tabular}

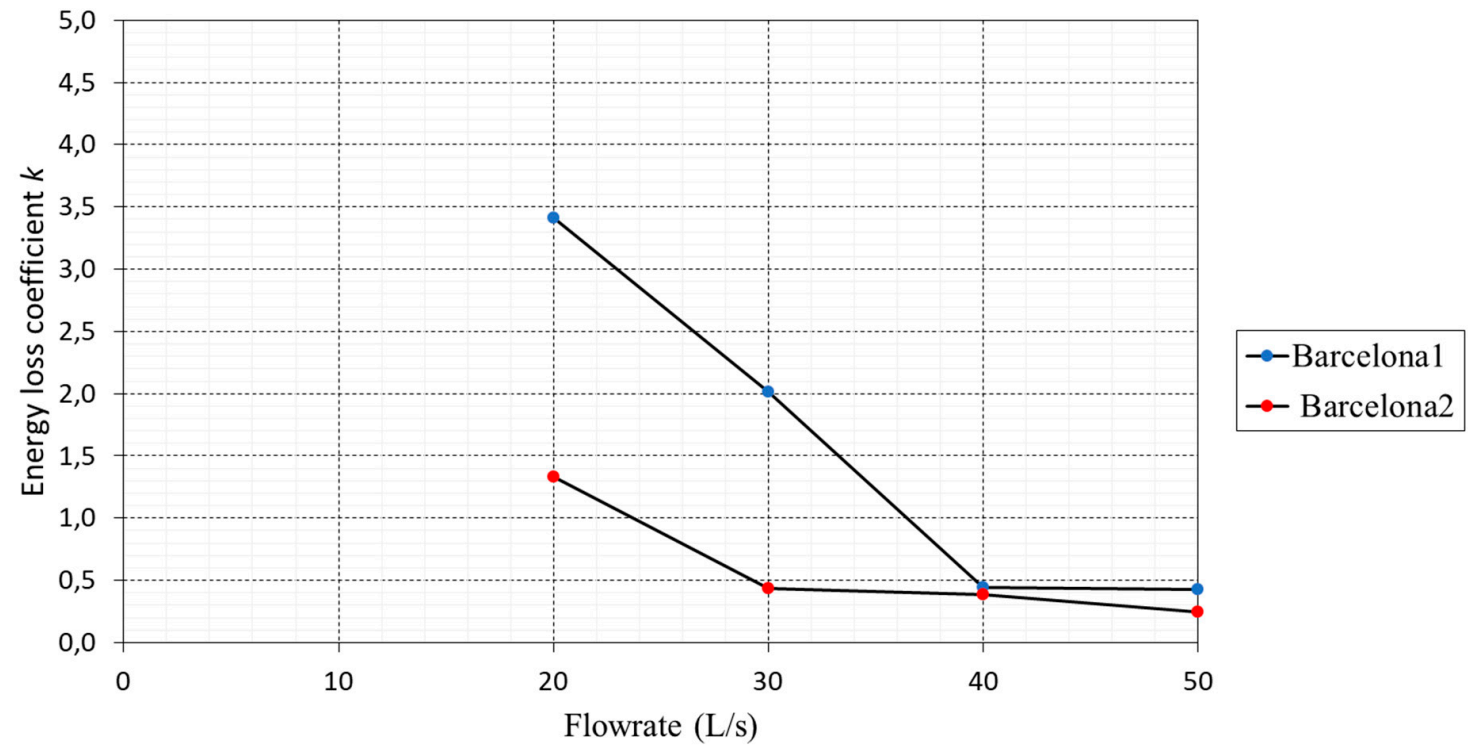

Figure 8. Mean energy loss coefficient $k$ for the two tested grates.

\subsection{Comparison of $k$ Values for Inlets and Multi-Jet Valves}

As there are no previous studies on energy loss coefficients in sewer grated inlets, in this study, one close reference used in water distribution networks, a multi-jet valve, was considered.

The comparison was proposed on the basic idea that a multi-jet regulation valve with a $100 \%$ opened area is the most similar hydraulic singularity with respect to a sewer grate. Void areas of sewer grates 
range from a few squared $\mathrm{cm}$ to tens of squared $\mathrm{cm}$. These values could be typical of small multi-jet valves. The multi-jet regulating valve, as shown in Figure 9, was specially developed to adjust the pressure losses of a hydraulic circuit, allowing the regulation (manual or automatic) of the flow or any other parameter linked to it such as pressure, level, etc.

In this case, in both sides of the multi-jet valve pressured flow conditions occurred, while in the case of surcharged flow through a sewer grated inlet, it passed from the pressure-flow condition (below the grate) to the atmospheric pressure condition (above the grate). Therefore, the flow through the inlet can be considered as a particular case of the multi-jet valve, with atmospheric pressure conditions on the outlet.

Furthermore, in Figure 9b, it can be seen that the range of variation of energy loss $k$ for a multi-jet regulating valve is very wide, so it can be observed that when the valve is around $25 \%$ opened, the value of $k$ is around 1000, while when it is completely open, the values are quite low (between 0 and 5). This situation (\% of opening of $100 \%$ ) is the case that can be compared to a grated inlet considered as a multi-jet regulation valve.

The hydraulic characteristics of a multi-jet valve can be found through hydraulic tests with precise measurements and visualization of the flow as well as the monitoring of the operation of valves already installed, allowing for the definition of the characteristics of the flow, the conditions of operation, and the selection and sizing of the multi-jet regulation valve. Figure 10 shows a zoom of the curve of $k$ values of a typical multi-jet regulation valve with a high grade of opening (from 75 to $100 \%$ ) [44]. Figure 10 also shows the values of $k$ for the grated inlets obtained in the laboratory tests. It can be observed that the obtained values ranged from 0.25 to 3.41 (close to the values suggested for the multi-jet valve with $100 \%$ of the valve open by the found reference).

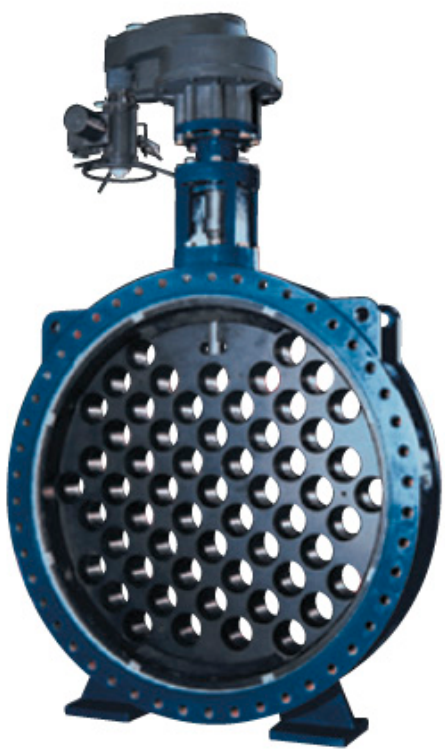

(a)

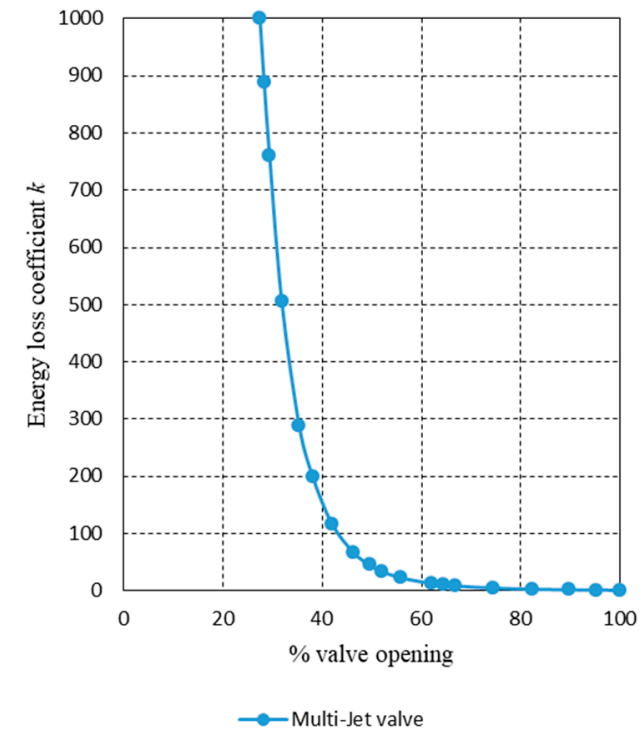

(b)

Figure 9. (a) Multi-jet regulation valve; (b) Graphic of energy loss $k$ [44].

The importance of determining the values of local loss of the grated inlet was to find a parameter useful for its hydraulic characterization. Furthermore, it is a value necessary to estimate the energy loss in a combined sewer network with surface flows generated by pressurized sewer pipes. This analysis is necessary in cases where a dual drainage approach is considered in the analysis of urban floods, when surface behavior in the streets and underground flow in the sewer system is calculated in a joint way [39]. In this case, the assessment of the flow transfer is a key point in the hydraulic analysis, 
and one way to characterize the inlet behavior is the inclusion of the local losses to properly determine the outflows from the sewer to the streets.

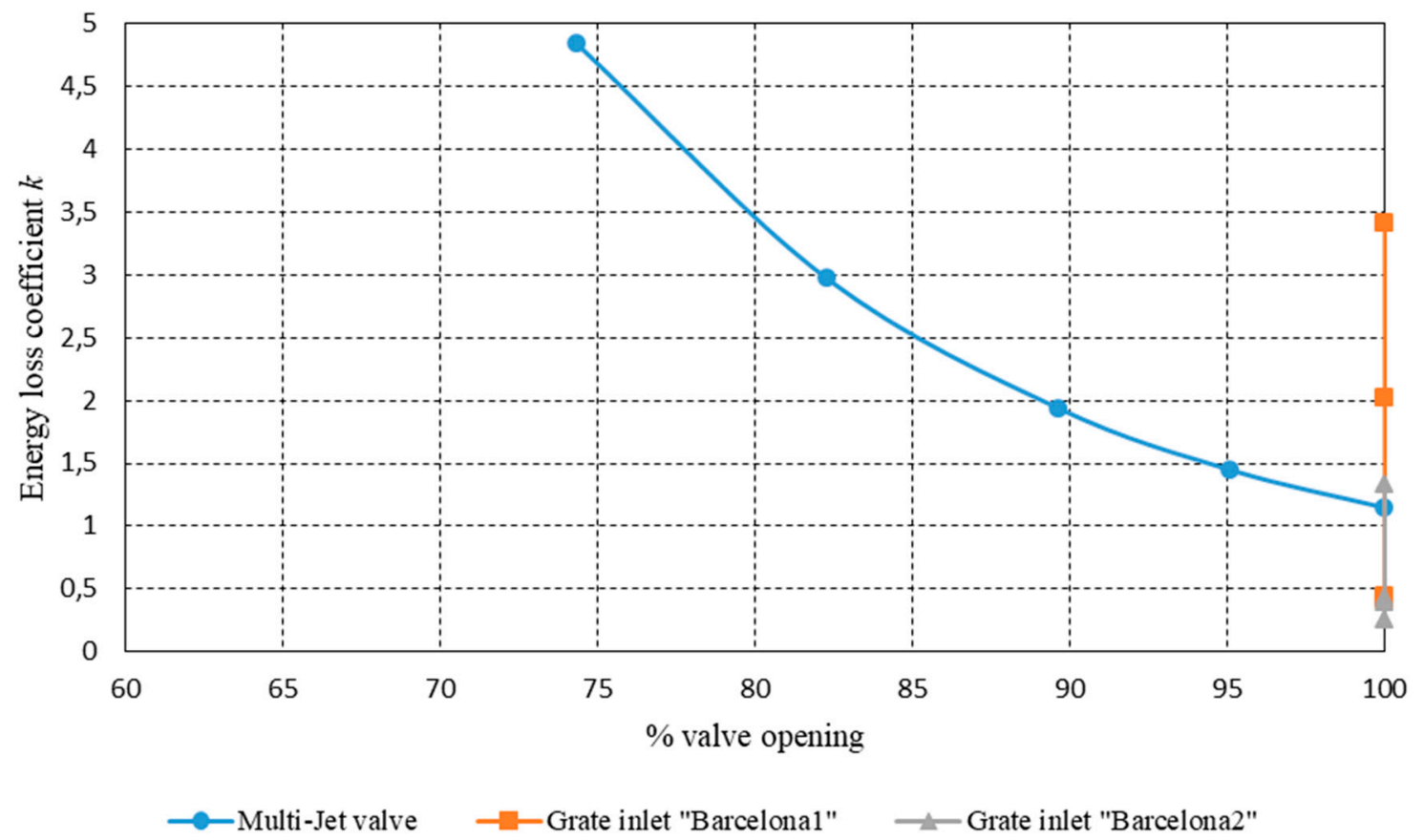

Figure 10. Energy loss coefficient vs. \% valve opening for a multi-jet valve [44].

Moreover, comparing the energy loss coefficient $k$ for surcharged manholes (0.93 for $2.59 \mathrm{~L} / \mathrm{s}$ ) [30] and the values obtained for the surcharged grated inlets in this study (between 0.25 for $20 \mathrm{~L} / \mathrm{s}$ and 3.41 for $50 \mathrm{~L} / \mathrm{s}$ ), it is possible to observe the nearness of the obtained estimations.

The tests carried out neglected the approaching flow on the surface. This limitation could have a significant influence on the final results. Additionally, it was possible to visualize in the laboratory that the values of local head loss decreased depending of the flow approaching on the surface, considering a constant outflow of the grate, although these cases were not considered in this experimental campaign. Notwithstanding, the influence of approaching flow was studied in manholes [30], and the obtained results showed that energy loss $k$ decreased according to the increase of circulating surface flow.

\section{Conclusions}

The energy loss coefficients of two different grated inlets were obtained for different combinations of platform geometry (changing longitudinal and transverse slope) and different surcharged outflow crossing the grate (from 20 to $50 \mathrm{~L} / \mathrm{s}$ ) produced by surcharged pipes. Tests were carried out in the hydraulic laboratory of UPC. The experimental campaign simulated the outflow from surcharged sewer systems through two grated inlets commonly used in Barcelona.

Local energy losses associated with the grated inlets were found by the measures of water level in 20 points and assuming an averaged value to consider a characteristic water level over the grate, in two conditions: once with the grate inlet placed and the other without the grate inlet. The difference between the two values can be considered as the energy loss.

In this way, the values of local energy loss coefficient $k$ were calculated for the two grates. For overflow through the grate between 20 and $50 \mathrm{~L} / \mathrm{s}$, the values of $k$ were from 0.42 to 3.41 for grate Barcelona1 and from 0.25 to 1.33 for grate Barcelona2, with similar values found in multi-jet valves for pressure flow networks. Moreover, although the range of the values of $k$ was quite limited, it was observed that these values decreased with the increment of the outflow for the two tested grates. 
The estimation of the energy loss coefficients did not include the surface flow on the street. The presence of circulating runoff could modify the values of $k$ depending on its amount. Moreover, the oscillation of water depths due to high turbulence of the flow can suppose errors in the measures of flow depth values, but in this case, their influence should not be as significant in the final results in terms of $k$ values due to the high number of points considered during the tests. Furthermore, bar errors were provided in the graphs of the results.

In summary, the main aim of this paper was to provide the order of magnitude of $k$ values to estimate head loss values in the case of overflow passing through a sewer grate. Moreover, a comparison with multi-jet valves and other references regarding surcharged manholes was undertaken, in order to confirm the goodness of the results obtained in this experimental study.

Future research in this line could focus on the effects of overland flow on $k$ values and, of course, to extend the results by testing other grates with different geometries.

Author Contributions: J.T.-A. contributed with the development of the experimental campaign, data collection, and first redaction of the manuscript; M.G. and B.R. proposed the research idea, the organization of the test facilities and experimental protocols, and reviewed the paper. All authors have read and agreed to the published version of the manuscript.

Acknowledgments: The authors acknowledge the hydraulic laboratory team of the UPC for their support during the experimental campaign.

Conflicts of Interest: The authors declare no conflict of interest.

\section{Appendix A}

Table A1. Average water depths of the 20 points above the surcharged box.

\begin{tabular}{|c|c|c|c|c|c|}
\hline \multirow[b]{2}{*}{$\begin{array}{c}\text { Transverse Slope } \\
\text { (\%) }\end{array}$} & \multirow[b]{2}{*}{$\begin{array}{l}\text { Longitudinal Slope } \\
\qquad(\%)\end{array}$} & \multirow[b]{2}{*}{$\begin{array}{c}\text { Flow Rate } \\
\text { (L/s) }\end{array}$} & \multicolumn{3}{|c|}{ Average Water Depth (m) } \\
\hline & & & Without Grate & $\begin{array}{c}\text { Grate } \\
\text { Barcelona1 }\end{array}$ & $\begin{array}{c}\text { Grate } \\
\text { Barcelona2 }\end{array}$ \\
\hline 2 & 0 & 20 & 0.0470 & 0.0562 & 0.0512 \\
\hline 2 & 2 & 20 & 0.0467 & 0.0577 & 0.0514 \\
\hline 2 & $\overline{4}$ & 20 & 0.0471 & 0.0571 & 0.0522 \\
\hline 2 & 6 & 20 & 0.0476 & 0.0584 & 0.0505 \\
\hline 2 & 8 & 20 & 0.0465 & 0.0554 & 0.0500 \\
\hline 2 & 10 & 20 & 0.0447 & 0.0524 & 0.0466 \\
\hline 2 & 0 & 30 & 0.0625 & 0.0737 & 0.0639 \\
\hline 2 & 2 & 30 & 0.0623 & 0.0732 & 0.0660 \\
\hline 2 & 4 & 30 & 0.0648 & 0.0741 & 0.0689 \\
\hline 2 & 6 & 30 & 0.0613 & 0.0743 & 0.0624 \\
\hline 2 & 8 & 30 & 0.0593 & 0.0740 & 0.0607 \\
\hline 2 & 10 & 30 & 0.0591 & 0.0764 & 0.0637 \\
\hline 2 & 0 & 40 & 0.0892 & 0.0925 & 0.0967 \\
\hline 2 & 2 & 40 & 0.0842 & 0.0897 & 0.0923 \\
\hline 2 & 4 & 40 & 0.0803 & 0.0895 & 0.0824 \\
\hline 2 & 6 & 40 & 0.0801 & 0.0881 & 0.0836 \\
\hline 2 & 8 & 40 & 0.0823 & 0.0852 & 0.0863 \\
\hline 2 & 10 & 40 & 0.0834 & 0.0845 & 0.0841 \\
\hline 2 & 0 & 50 & 0.0998 & 0.1046 & 0.1007 \\
\hline 2 & 2 & 50 & 0.0994 & 0.1028 & 0.1033 \\
\hline 2 & 4 & 50 & 0.1037 & 0.1043 & 0.1057 \\
\hline 2 & 6 & 50 & 0.1042 & 0.1048 & 0.1043 \\
\hline 2 & 8 & 50 & 0.0927 & 0.1106 & 0.1026 \\
\hline 2 & 10 & 50 & 0.0922 & 0.1099 & 0.1017 \\
\hline
\end{tabular}

\section{References}

1. Aronica, G.T.; Lanza, L.G. Drainage efficiency in urban areas: A case study. Hydrol. Process. 2005, 19, 1105-1119. [CrossRef] 
2. Despotovic, J.; Plavšić, J.; Stefanovic, N.; Pavlovic, D. Inefficiency of storm water inlets as a source of urban floods. Water Sci. Technol. 2005, 51, 139-145. [CrossRef]

3. Gómez, M.; Macchione, F.; Russo, B. Methodologies to study the surface hydraulic behaviour of urban catchments during storm events. Water Sci. Technol. 2011, 63, 2666-2673. [CrossRef]

4. Comport, B.C.; Thornton, C.I. Hydraulic Efficiency of Grate and Curb Inlets for Urban Storm Drainage. J. Hydraul. Eng. 2012, 138, 878-884. [CrossRef]

5. Martins, R.; Leandro, J.; Fernandes de Carvalho, R. Characterization of the hydraulic performance of a gully under drainage conditions. Water Sci. Technol. 2014, 69, 2423-2430. [CrossRef] [PubMed]

6. Palla, A.; Colli, M.; Candela, A.; Aronica, G.T.; Lanza, L.G. Pluvial flooding in urban areas: The role of surface drainage efficiency. J. Flood Risk Manag. 2016, 11, S663-S676. [CrossRef]

7. Kemper, S.; Schlenkhoff, A. Experimental study on the hydraulic capacity of grate inlets with supercritical surface flow conditions. Water Sci. Technol. 2019, 79, 1717-1726. [CrossRef] [PubMed]

8. Gómez, M.; Macchione, F.; Russo, B. Hydraulic behavior of urban streets during storm events. Ing. Hidraul. en Mexico 2009, 24, 51-62.

9. Gómez, M.; Russo, B. Methodology to estimate hydraulic efficiency of drain inlets. Proc. Inst. Civ. Eng.-Water Manag. 2011, 164, 81-90. [CrossRef]

10. Russo, B.; Gómez, M.; Tellez, J. Methodology to estimate the hydraulic efficiency of nontested continuous transverse grates. J. Irrig. Drain. Eng. 2013, 139, 864-871. [CrossRef]

11. Rubinato, M.; Lee, S.; Martins, R.; Shucksmith, J.D. Surface to sewer flow exchange through circular inlets during urban flood conditions. J. Hydroinform. 2018, 20, 564-576. [CrossRef]

12. Martins, R.; Rubinato, M.; Kesserwani, G.; Leandro, J.; Djordjevic, S.; Shucksmith, J.D. On the characteristics of velocities fields in the vicinity of manhole inlet grates during flood events. Water Resour. Res. 2018, 54, 6408-6422. [CrossRef]

13. Brown, S.A.; Schall, J.D.; Morris, J.L.; Doherty, C.L.; Stein, S.M.; Warner, J.C. Hydraulic Engineering Circular No. 22, Third Edition (2009) Revised 2013; Publication No. FHWA-NHI-10-009; U.S. Dept. of Transportation: Lakewood, CO, USA, 2009.

14. Gómez, M.; Russo, B. Comparative Study among Different Methodologies to Determine Storm Sewer Inlet Efficiency from Test Data: HEC22 Methodology vs. UPC Method. In Water Resources management III; Publisher is WIT Press: Algarve, Portugal, 2005; pp. 623-632.

15. Rubinato, M.; Martins, R.; Kesserwani, G.; Leandro, J.; Djordjević, S.; Shucksmith, J. Experimental calibration and validation of sewer/surface flow exchange equations in steady and unsteady flow conditions. J. Hydrol. 2017, 552, 421-432. [CrossRef]

16. Freire Diogo, A.; Antunes do Carmo, J. Peak flows and stormwater networks design—current and future management of urban surface watersheds. Water 2019, 11, 759. [CrossRef]

17. Diogo, A.F.; Tiago Barros, L.; Santos, J.; Santos Temido, J. An effective and comprehensive model for optimal rehabilitation of separate sanitary sewer systems. Sci. Total. Environ. 2018, 612, 1042-1057. [CrossRef]

18. Velasco, M.; Russo, B.; Cabello, À.; Termes, M.; Sunyer, D.; Malgrat, P. Assessment of the effectiveness of structural and nonstructural measures to cope with global change impacts in Barcelona. J. Flood Risk Manag. 2016, 11, S55-S68. [CrossRef]

19. Russo, B.; Sunyer, D.; Velasco, M.; Djordjević, S. Analysis of extreme flooding events through a calibrated 1D/2D coupled model: The case of Barcelona (Spain). J. Hydroinformatics 2014, 17, 473-491. [CrossRef]

20. Pedersen, F.B.; Mark, O. Head losses in storm sewer manholes: Submerged jet theory. J. Hydraul. Eng. 1990, 116, 1317-1328. [CrossRef]

21. Marsalek, J. Head losses junction of two opposing lateral sewers. In Proceedings of the 4th International Conference on urban Storm Drainage, Lausanne, Switzerland, September 1987.

22. Hare, C. Magnitude of hydraulic losses at junctions in piped drainage systems. In Conference on Hydraulics in Civil Engineering (1st: 1981: Sydney, N.S.W.). Conference on Hydraulics in Civil Engineering 1981: Preprints of Papers; Civil Engineering Transaction, Institute of Civil Engineers: Barton, Australia, 1983; pp. 71-77.

23. Howarth, D.A.; Saul, A.J. Energy loss coefficient at manholes. In Proceedings of the 3rd International Conference on Urban Storm Drainage, Gothenburg, Sweden, 4-8 June 1984.

24. Lindvall, G. Head losses at surcharged manholes with a main pipe and a 90 degrees lateral. In Proceedings of the 3rd International Conference on Urban Storm Drainage, Gothenburg, Sweden, 4-8 June 1984. 
25. Djordjević, S.; Prodanović, D.; Maksimović, Č.; Ivetić, M.; Savic, D. SIPSON-Simulation of Interaction between Pipe flow and Surface Overland flow in Networks. Water Sci. Technol. 2005, 52, 275-283. [CrossRef]

26. Rossman, L.A. Storm Water Management Model Quality Assurance Report: Dynamic Waver Flow Routing; U.S. Environmental Protection Agency: Washington, DC, USA, 2006.

27. O'Loughlin, G.; Stack, B. Algorithms for Pit Pressure Changes and Head Losses in Stormwater Drainage Systems. Glob. Solut. Urban Drain. 2002. [CrossRef]

28. Del Giudice, G.; Hager, W.H. Supercritical flow in $45^{\circ}$ junction manhole. Irrig. Drainage Eng. 2001, 127, 100-108. [CrossRef]

29. Del Giudice, G.; Gisonni, C.; Hager, W.H. Supercritical Flow in Bend Manhole. J. Irrig. Drain. Eng. 2000, 126, 48-56. [CrossRef]

30. Arao, S.; Kusuda, T.; Moriyama, K.; Hiratsuka, S.; Asada, J.; Hirose, N. Energy losses at three-way circular drop manholes under surcharged conditions. Water Sci. Technol. 2012, 66, 45-52. [CrossRef] [PubMed]

31. Rubinato, M. Physical Scale Modelling of Urban Flood Systems. Ph.D. Thesis, University of Sheffield, Sheffield, UK, 2015.

32. Rubinato, M.; Martins, R.; Shucksmith, J.D. Quantification of energy losses at a surcharging manhole. Urban Water J. 2018, 15, 234-241. [CrossRef]

33. Bazin, P.-H.; Nakagawa, H.; Kawaike, K.; Paquier, A.; Mignot, E. Modeling flow exchanges between a street and an underground drainage pipe during urban floods. J. Hydraul. Eng. 2014. [CrossRef]

34. Tellez-Alvarez, J.D. Image Processing and Experimental Techniques to Characterize the Hydraulic Performance of Grate Inlets. Ph.D. Thesis, Technical University of Catalonia, Barcelona, Spain, May 2019.

35. Lahiouel, Y.; Haddad, A.K.; Chaoui, K. Evaluation of head losses in fluid transportation networks. Sci. Technol. B 2015, 23, 89-94.

36. Vano Engineering. Available online: https://vanoengineering.wordpress.com/2012/12/30/head-loss-coefficients/ (accessed on 22 February 2019).

37. Russo, B.; Velasco, M.; Monjo, R.; Martínez-Gomariz, E.; Sánchez, D.; Domínguez, J.L.; Gabàs, A.; Gonzalez, A. Evaluación de la resiliencia de los servicios urbanos frente a episodios de inundación en Barcelona. El proyecto RESCCUE. Ing. Agua 2020, 24, 101-118. [CrossRef]

38. Russo, B.; Gómez, M.; Macchione, F. Pedestrian hazard criteria for flooded urban areas. Nat. Hazards 2013, 69, 251-265. [CrossRef]

39. Pfister, M.; Gisonni, C. Head losses in junction manholes for free surface flows in circular conduits. J. Hydraul. Eng. 2014, 140, 06014015. [CrossRef]

40. Zhao, C.-H.; Zhu, D.Z.; Rajaratnam, N. Experimental study of surcharged flow at combining sewer junctions. J. Hydraul. Eng. 2006, 132, 1259-1271. [CrossRef]

41. Ramamurthy, A.S.; Zhu, W. Combining flows in $90^{\circ}$ junctions of rectangular closed conduits. J. Hydraul. Eng. 1997, 12311, 1012-1019. [CrossRef]

42. Gómez, M.; Russo, B.; Tellez-Alvarez, J. Experimental investigation to estimate the discharge coefficient of a grate inlet under surcharge conditions. Urban Water J. 2019, 16, 85-91. [CrossRef]

43. Gómez, M.; Hidalgo Rabasseda, G.; Russo, B. Experimental campaign to determine grated inlet clogging factors in an urban catchment of Barcelona. Urban Water J. 2013, 10, 50-61. [CrossRef]

44. Hydrostec. Available online: http://www.hydrostec.com.br/ingles/catalogo/circuitos_pressurizados/B30-15-0. pdf (accessed on 24 February 2019).

(C) 2020 by the authors. Licensee MDPI, Basel, Switzerland. This article is an open access article distributed under the terms and conditions of the Creative Commons Attribution (CC BY) license (http://creativecommons.org/licenses/by/4.0/). 